\title{
MET overexpression, gene amplification and relevant clinicopathological features in gastric adenocarcinoma
}

\author{
Jing Zhang ${ }^{1}$, Lei Guo ${ }^{1}$, Xiuyun Liu ${ }^{1}$, Wenbin $\mathrm{Li}^{1}$, Jianming Ying ${ }^{1}$ \\ ${ }^{1}$ Department of Pathology, National Cancer Center/Cancer Hospital, Chinese Academy of Medical Sciences and Peking Union \\ Medical College, Beijing, 100021, China \\ Correspondence to: Jianming Ying, email: jmying@hotmail.com \\ Keywords: gastric cancer, MET overexpression, MET gene amplification, biomarker, immunohistochemistry \\ Received: October 21,2016 Accepted:December 13,2016 Published: December 30, 2016
}

\section{ABSTRACT}

This study was conducted to investigate the expression of MET in Chinese gastric adenocarcinoma cohort, the correlation between MET overexpression and clinical pathological features, HER2 expression and MET gene amplification. A total of $\mathbf{8 1 6}$ gastric adenocarcinoma patients were included and MET and HER2 immunohistochemical (IHC) staining were performed. IHC and dual-color silver in situ hybridization analysis were performed in the tissue microarrays, constructed from the 240 patients who were randomly selected. MET overexpression (IHC $3+$ ) was observed in $6.0 \%(49 / 816)$ of the cohort. MET overexpression rate was higher in patients with poor prognostic factors, such as clinical stages III/IV $(p=0.012)$ and pathologic stages T3/T4 $(p=0.027)$. The HER2 overexpression $($ IHC $3+)$ rate was $8.8 \%(72 / 816)$ and MET overexpression rate was higher in HER2 positive patients $(9.7 \%, 7 / 72)$. A high concordance rate (94.6\%) between MET overexpression and gene amplification was demonstrated. Therefore, MET overexpression could serve as a prognostic biomarker and a potential therapeutic target for gastric cancer.

\section{INTRODUCTION}

Gastric adenocarcinoma (GC) continues to be a significant public health threat. It is the fourth most common cancer and the second leading cause of cancer related death worldwide $[1,2]$. The prognosis of patients with GC remains poor. The 5-year overall survival rate for advanced or metastatic disease remains $<30 \%$ [3]. Trastuzumab, a recombinant monoclonal antibody targeting human epidermal growth factor receptor type 2 (HER2), is now being applied in GC treatment. It significantly improved the overall survival in patients with HER2 overexpression [4]. However, HER2 overexpression only occurs in approximately $13 \%$ of the Chinese GC patients [5]. Thus, more targeted agents for treating GC patients are in great needs.

Mesenchymal-epithelial transition factor (MET) is the so called hepatocyte growth factor (HGF) receptor. MET overexpression and its gene amplification have recently been indicated as survival prognostic factors for many cancers including GC. Multiple studies have shown that MET is also a potential therapeutic target in advanced or metastatic GC [6-8]. Interactive crosstalk between MET and other receptors such as epidermal growth factor receptor type 1 (EGFR) and HER2 underlies a key role in resistance to other Receptor Tyrosine Kinasetargeted therapies. For example, previous studies reported that MET pathways activation represented novel drug resistance mechanism of lapatinib unresponsiveness in HER2 positive gastric cancer [9, 10]. So combinational therapy may be more effective in treating HER2 positive gastric cancer patients with MET-induced resistance [11]. Patients with $M E T$ gene amplification showed transient sensitivity to the targeted MET inhibitor-Crizotinib [12, 13]. There was also case report about durable complete response of metastatic gastric cancer with anti-MET therapy [14]. Rilotumumab and Onartuzumab are both monoclonal antibodies that are MET inhibitors. Results from phase II clinical trials of these two MET inhibitors were encouraging [15] and currently there are multiple ongoing phase III studies on these two agents and other MET inhibitors [16, 17].

Although MET targeted agents for gastric cancer have been intensively investigated, the categorizing the MET expression level into under/over expression is lacking standardized scoring system. Data from previous 
studies have shown MET overexpression rates vary from $4 \%$ to $82.4 \%[18,19]$, and $M E T$ gene amplification rates vary from $2 \%$ to $24 \%$ [6], which may be the results of different patient populations and the lack of standardized scoring system used to categorize the expression level in these studies. In addition, the relationship between MET overexpression and MET gene amplification has rarely been studied. The primary objective of our study is to develop a modified score system for categorizing MET expression level using as standardized criteria, and assessed the incidence of MET overexpression in a large Chinese GC cohort. The relationship between MET overexpression and gene amplification and clinicopathological parameters including HER2 expression were also investigated in this study.

\section{RESULTS}

\section{MET expression condition in chinese GC cohort without history of treatment}

A total of 816 patients were evaluated by IHC. The patients' clinicopathological characteristics were summarized in Table 1. The median age was 61 years (range from 23 to 84 years), with majority of male (73.9\%). Of all patients, there were 318 cases $(39 \%)$ of intestinal type by Lauren's classification. Approximately one-third was primary gastroesophageal junction (GEJ) adenocarcinoma and one-half was primary gastric body (GB) cancer. The tumors were poorly differentiated in $76.1 \%$, moderately differentiated in $20.3 \%$. There were $28.6 \%$ patients in clinical stage I, $19.9 \%$ in clinical stage II and $50.0 \%, 1.6 \%$ in stages III and IV. There were $23.7 \%$ patients at pathologic stage $\mathrm{T} 1$, with $12.3 \%$, $29.2 \%$, and $34.9 \%$ at stages T2, T3, and T4, respectively. About pathologic $\mathrm{N}$ stages, there were $35.3 \%, 17.2 \%$, $18.6 \%, 28.9 \%$ patients at N0, N1, N2, and N3 stages respectively. Of the 816 patients, $49(6.0 \%)$ patients were scored $3+$ based on the modified scoring system, thus were considered MET overexpression positive $(3+)$, while $767(94.0 \%)$ were identified as MET overexpression negative (with IHC score of $0 / 1+/ 2+$ ). Heterogeneous overexpression of MET was found in 51\% (25/49) MET IHC $3+$ (overexpression) patients (Table 2).

\section{Relationship between MET overexpression and clinicopathological characteristics}

Table 1 summarized MET overexpression status by subgroup of clinicopathological characteristics. Significant difference in MET overexpression was found in tumor clinical stage and pT status. MET overexpression was correlated with clinical stages with $8.1 \%(34 / 421)$ overexpression in III/IV stages patients and $3.8 \%(15 / 395)$ in I/II stages $(\boldsymbol{p}=0.012)$. MET was overexpressed in $7.5 \%(39 / 484)$ of $\mathrm{pT} 3 / \mathrm{pT} 4$ stage patients which is significantly higher than that in pT1/T2 stages $(3.4 \%, 10 / 283)$. No correlation was observed between MET overexpression and age group, sex, tumor location, Lauren classification and tumor differentiation.

\section{MET expression and HER2 expression}

The correlation between MET expression and HER2 expression in GC was summarized in Table 3. The positive rate for HER2 was $8.8 \%$ (72/816) and MET overexpression was higher in HER2 positive patients $(9.7 \%, 7 / 72)$ than that in HER2 negative $(5.1 \%, 32 / 622)$, although there was no significant difference $(\boldsymbol{p}=0.164)$.

\section{Concordance of MET overexpression and MET gene amplification}

Dual-color silver in situ hybridization (DISH) analysis was performed in 240 GC and GEJ adenocarcinoma cases randomly selected, with high cell density ( $>30 \%$ tumor cells/area) were selected. Finally, 205 fragments met the inclusion criteria for the study, including 16 cases with IHC $3+, 78$ cases with IHC $2+$, and 111 cases with IHC 0/1+. MET gene amplification was observed in $62.5 \%(10 / 16)$ of MET IHC $3+$ cases, $2.6 \%(5 / 189)$ of MET IHC $2+/ 1+/ 0$ cases, showing a concordance rate of $94.6 \%$ between IHC and DISH with a relatively low $\boldsymbol{k}$ value of 0.3 (Table 4).

\section{DISCUSSION}

Due to the inconsistent scoring criteria used in MET IHC interpretation in previous studies, in which the positivity rate of MET overexpression varying from $4 \%$ to $82.4 \%[18,20,21]$, this study demonstrated an applicable MET IHC scoring system in gastric cancer by combining expression proportion and intensity. Similar to Hofmann's criteria for HER2 IHC scoring [22], we chose $10 \%$ as a cut-off value which also has been used in other studies [23]. In the study of Sang Y Ha et al. strong staining in $>10 \%$ of tumor cells was interpreted as MET IHC 3+ and all nine MET IHC 3+ cases showed MET gene amplification [24]. Our results showed that MET overexpression (IHC 3+) was detected in $6.0 \%$ (49/816) of the cohort. A high concordance rate $(94.6 \%)$ between MET overexpression and gene amplification was demonstrated (Figure 1). MET expression heterogeneity was frequently found in MET overexpression cases, with $51 \%(25 / 49)$ MET IHC 3+ (overexpression) cases whose expression proportion were lower than $50 \%$, while there were only $15.7 \%$ and $24.4 \%$ respectively in $2+$ and $1+/ 0$ patients (Table 2 and Figure 2). MET heterogeneity is definitely an issue that we should pay more attention to in our further studies.

Whether cases with MET IHC 2+ should be defined as MET overexpression is controversial. Some 
Table 1: Correlation between MET expression status and GC clinicopathological parameters

\begin{tabular}{|c|c|c|c|c|}
\hline IHC (\%) & $\begin{array}{c}\text { Grouping } \\
\text { overall }\end{array}$ & $\begin{array}{c}\text { MET } \\
\text { Negative }\end{array}$ & $\begin{array}{c}\text { MET } \\
\text { Positive }\end{array}$ & $P$ value \\
\hline Pathologic features & $\mathrm{n}=816(\%)$ & $\mathrm{n}=767(94.0)$ & $\mathrm{n}=49(6.0)$ & \\
\hline Age at diagnosis & & & & 0.769 \\
\hline$\geq 60$ years & $448(54.9)$ & $420(93.8)$ & $28(6.3)$ & \\
\hline$<60$ years & $368(45.1)$ & $347(94.3)$ & $21(5.7)$ & \\
\hline Sex & & & & 0.131 \\
\hline Male & $603(73.9)$ & $562(93.2)$ & $41(6.8)$ & \\
\hline Female & $213(26.1)$ & $205(96.2)$ & $8(3.8)$ & \\
\hline Tumor location & & & & 0.064 \\
\hline GEJ & $253(31.0)$ & $232(91.7)$ & $21(8.3)$ & \\
\hline GB & $414(50.7)$ & 397(95.9) & $17(4.1)$ & \\
\hline GA & $149(18.3)$ & $138(92.6)$ & $11(7.4)$ & \\
\hline Lauren classification & & & & 0.153 \\
\hline Intestinal & $318(39.0)$ & $294(92.5)$ & $24(7.5)$ & \\
\hline Mixed & $233(28.6)$ & 218(93.6) & $15(6.4)$ & \\
\hline Diffuse & $265(32.5)$ & $255(96.2)$ & $10(3.8)$ & \\
\hline Tumor differentiation & & & & 0.904 \\
\hline Well & $29(3.6)$ & $27(93.1)$ & $2(6.9)$ & \\
\hline Moderately & $166(20.3)$ & $155(93.4)$ & $11(6.6)$ & \\
\hline Poorly & $621(76.1)$ & $585(94.2)$ & $36(5.8)$ & \\
\hline Clinical stages & & & & 0.012 \\
\hline $\mathbf{I} / \mathbf{I I}$ & $395(48.4)$ & $380(96.2)$ & $15(3.8)$ & \\
\hline III/IV & $421(51.6)$ & $387(91.9)$ & $34(8.1)$ & \\
\hline Clinical stages & & & & 0.038 \\
\hline I & $233(28.6)$ & $233(95.7)$ & $10(4.3)$ & \\
\hline II & $162(19.9)$ & $157(96.9)$ & $5(3.1)$ & \\
\hline III & $408(50.0)$ & $374(91.7)$ & $34(8.3)$ & \\
\hline IV & $13(1.6)$ & $13(100)$ & $0(0)$ & \\
\hline pT status & & & & 0.021 \\
\hline pT1/2 & 293(35.9) & $283(96.6)$ & $10(3.4)$ & \\
\hline pT3/4 & $523(64.1)$ & $484(92.5)$ & $39(7.5)$ & \\
\hline pT status & & & & 0.027 \\
\hline pT1 & $193(23.7)$ & 189(97.9) & $4(2.1)$ & \\
\hline pT2 & $100(12.3)$ & $94(94.0)$ & $6(6.0)$ & \\
\hline pT3 & $238(29.2)$ & $224(94.1)$ & $14(5.9)$ & \\
\hline pT4 & $285(34.9)$ & $260(91.2)$ & $25(8.8)$ & \\
\hline pN status & & & & 0.644 \\
\hline pNo & $288(35.3)$ & $269(93.4)$ & $19(6.6)$ & \\
\hline $\mathrm{pN} 1 / 2 / 3$ & $528(64.7)$ & $498(94.3)$ & $30(5.7)$ & \\
\hline pN status & & & & 0.801 \\
\hline pNo & $288(35.3)$ & $269(93.4)$ & $19(6.6)$ & \\
\hline pN1 & $140(17.2)$ & $134(95.7)$ & $6(4.3)$ & \\
\hline pN2 & $152(18.6)$ & $142(93.4)$ & $10(6.6)$ & \\
\hline pN3 & $236(28.9)$ & $222(94.1)$ & $14(5.9)$ & \\
\hline
\end{tabular}


Table 2: MET expression proportion in different expression intensity in GC

\begin{tabular}{|c|c|c|c|c|}
\hline \multirow{2}{*}{$\begin{array}{l}\text { Expression } \\
\text { proportion }\end{array}$} & \multicolumn{3}{|c|}{ MET IHC } & \multirow{2}{*}{$\begin{array}{c}P \text { value }<0.001 \\
\text { Total }\end{array}$} \\
\hline & $3+$ & $2+$ & $1+/ 0$ & \\
\hline$\geq 50 \%$ & $24(49.0)$ & $311(84.3)$ & $301(75.6)$ & $636(77.9)$ \\
\hline$<50 \%$ & $25(51.0)$ & $58(15.7)$ & $97(24.4)$ & $180(22.1)$ \\
\hline Total & $49(6.0)$ & $369(45.2)$ & $398(48.8)$ & 816 \\
\hline
\end{tabular}

Table 3: Correlation between MET expression status and HER2 expression status in GC

\begin{tabular}{lccc}
\hline \multirow{2}{*}{ HER2 (\%) } & \multicolumn{2}{c}{ MET } & P value $=\mathbf{0 . 1 6 4}$ \\
\cline { 2 - 4 } & $\mathbf{3 +}$ & $\mathbf{0 / 1 + / 2 +}$ & Total \\
\hline $\mathbf{0} / \mathbf{1 +}$ & $32(5.1)$ & $590(94.9)$ & $622(76.2)$ \\
$\mathbf{2 +}$ & $10(8.2)$ & $112(91.8)$ & $122(15)$ \\
$\mathbf{3}+$ & $7(9.7)$ & $65(90.3)$ & $72(8.8)$ \\
\hline Total & $49(6.0)$ & $767(94)$ & 816 \\
\hline
\end{tabular}

Table 4: Correlation between MET overexpression and gene amplification in GC

\begin{tabular}{|c|c|c|c|c|}
\hline \multirow{2}{*}{ MET DISH (\%) } & \multicolumn{3}{|c|}{ MET IHC } & \multirow{2}{*}{ Total } \\
\hline & $3+$ & $2+$ & $1+/ 0$ & \\
\hline МET/CEP7 $\geq 2$ & $10(62.5)$ & $3(3.8)$ & $2(1.8)$ & $15(7.3)$ \\
\hline МЕТ/СЕР7<2 & $6(37.5)$ & $75(96.2)$ & $109(98.2)$ & $190(92.7)$ \\
\hline Total & $16(7.8)$ & $78(38.1)$ & $111(54.1)$ & 205 \\
\hline
\end{tabular}

studies considered MET IHC 2+ as MET overexpression cases which is different from ours [25]. Previous study has shown that IHC $3+$ and gene amplification were significantly associated with poor prognosis, but not for IHC 2+[26]. Meanwhile, in our study the MET IHC 2+ patients were rare with gene amplification $(3.8 \%, 3 / 78)$. However, Sang Y Ha et al. also revealed MET IHC 2+ cases showed similarly poor survival as those with MET IHC $3+$ cases, further confirmation should be performed [24].

The membranous and/or cytoplasmic expression levels of MET were considered while defining MET overexpression status. Jianji Jiang, et al have indicated that only simultaneous membranous and cytoplasmic overexpression of MET was significantly correlated with MET gene amplification and showed shorter overall survival and disease-free survival compared with patients without MET overexpression [27]. In our study MET overexpression status defined solely base upon membranous level, cytoplasm level or simultaneous membranous and cytoplasmic level was not found to be correlated with any clinicopathological characteristics.

Other semi-quantitative methods for evaluating MET IHC staining were also explored. In the study of Tiankang Guo et al., proportional score $(0,0 \% ; 1,1-25 \%$;
$2,26 \%-50 \% ; 3,51 \%-75 \%$ and $4,76-100 \%)$ and intensity score $(0$, negative; 1 , weak; 2 , medium and 3 , strong) were summed to obtain a total score. A score $\geq 3$ was considered as positive expression [28]. They reported the positive rate of MET was 59.18\% and expression of MET protein was significant correlated with lymph node metastasis $(\boldsymbol{p}=0.041)$. We applied the method in our study and summarized the result in Table 5. MET positive rate was $87.9 \%$ and although expression of MET protein was significant correlated with lymph node metastasis $(\boldsymbol{p}<0.001)$, MET positive was higher in pN0 stage. We had contradictory conclusion with a large sample, so this method maybe not scientific and maybe IHC intensity was the only factor need to be considered in MET IHC scoring system.

We also explored the modified $\mathrm{H}$-score system mentioned in the review of Luigi Marano et al. [23]. The analysis result was summarized in Table 6. MET positive rate was $42.0 \%$. Significant difference in MET overexpression was found in tumor location, Lauren classification, clinical stages, $\mathrm{pT}$ status and $\mathrm{pN}$ status. MET overexpression was significant higher in I/II stage, pT1/2 and $\mathrm{pN} 0$ cases. We would draw a contrary conclusion to the previous studies mentioned in this review and other systematic review and meta-analysis [29]. 
Previous studies have indicated MET overexpression activated MET signal pathway to promote tumor cell growth, survival, migration, and invasion as well as tumor angiogenesis $[19,26,30,31]$. In our study, one of the largest studies to date, MET overexpression was found to be related to clinical stages and pT stages. Advanced pT stages supported MET proto-oncogene activation for deeply infiltrating in gastric cancers. It indicated that
MET overexpression was poor prognostic factor. That is consistent with many other reports [21, 25, 29]. One study has reported that overexpression of MET tended to be associated with poor prognosis, but there were no significant effects after adjustment for potentially confounding factors with multivariate analysis [32]. Definitely this speculation should be further validated by directly analysis the correlation between MET
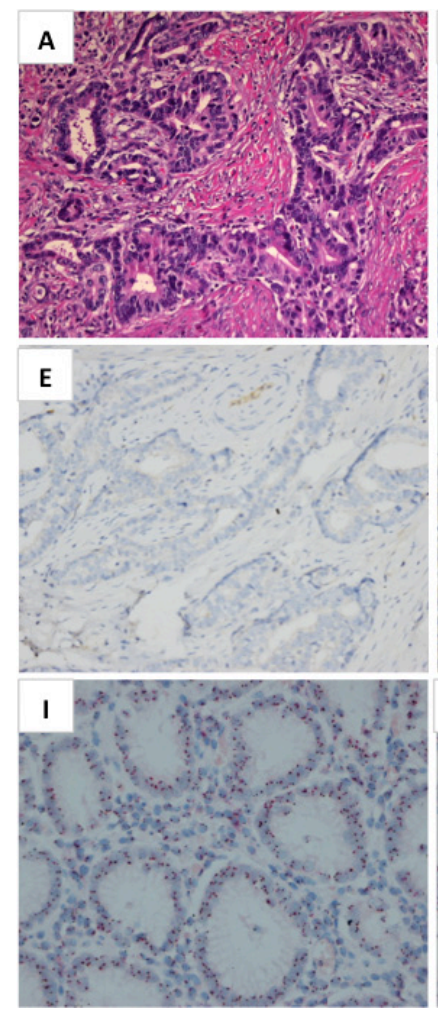
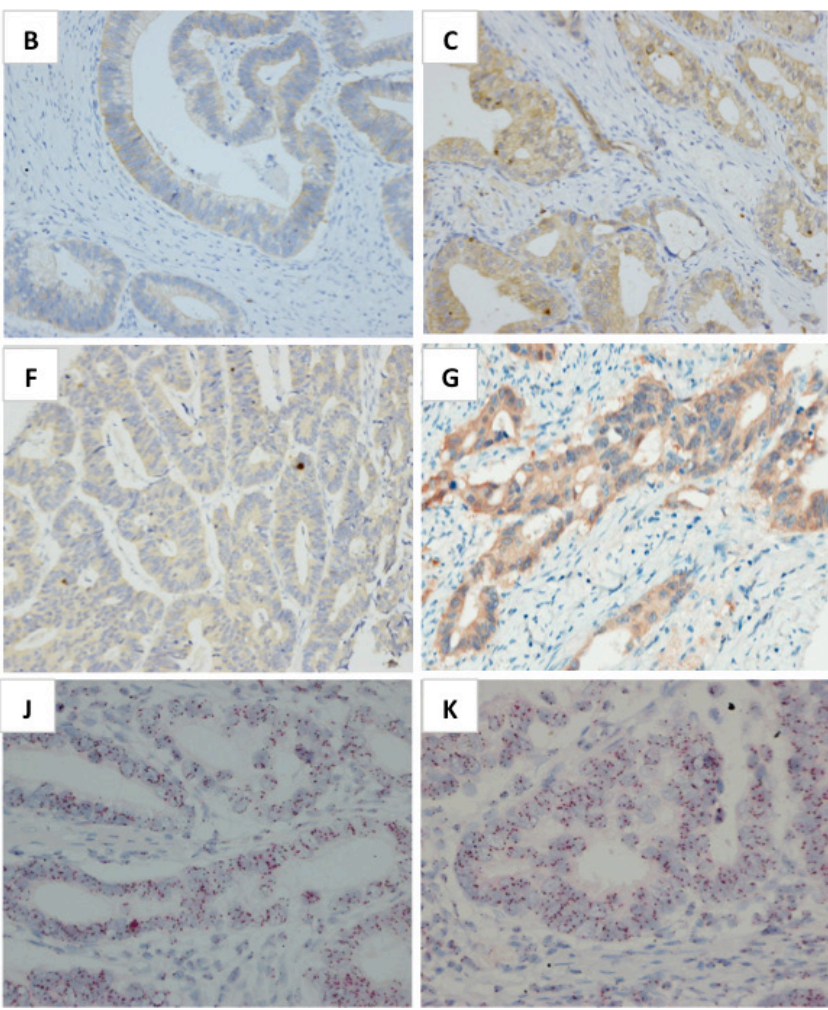
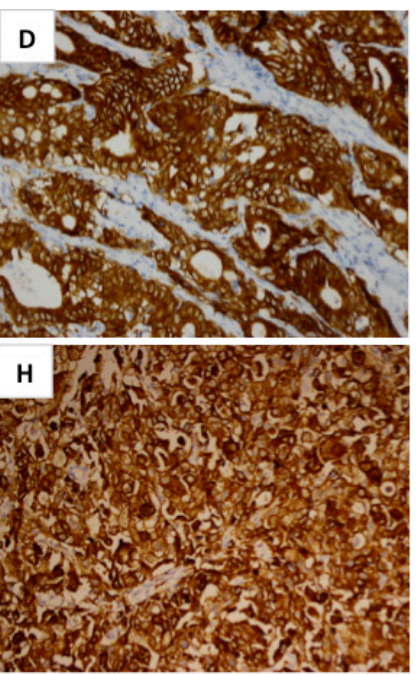

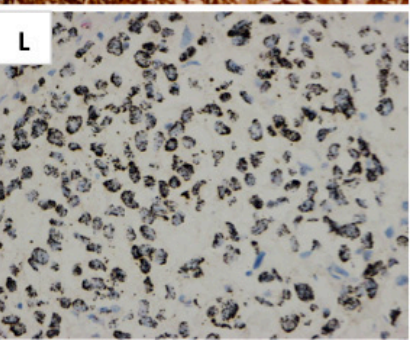

Figure 1: Representative microphotographs $(\mathrm{A}-\mathrm{H}, \times 200)$ of gastric cancer $\mathrm{H} \& \mathrm{E}$ staining A. and MET expression scored as 1+ B. 2+ C. 3+ D. in the membrane. And MET expression interpreted as 0 E. $1+$ F. $2+$ G. and 3+ H. in both membrane and cytoplasm of tumor cells. Representative microphotographs of MET DISH (I-L, $\times 400$ ): disomy of normal gastric musco (IHC -) I. IHC $1+\mathbf{J}$. IHC $2+\mathbf{K}$. and gene amplification $\mathbf{L}$. cases by DISH are shown.
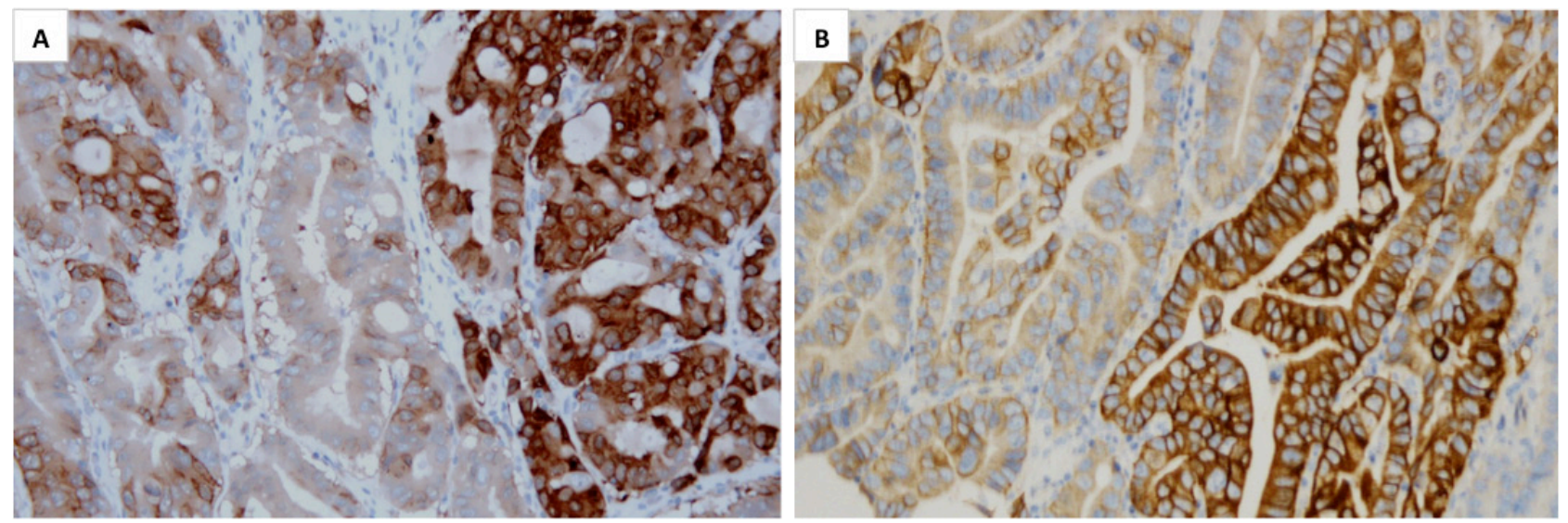

Figure 2: Representative microphotographs of MET overexpression heterogeneity are showed $($ A\&B, $\times 200)$. Positive IHC staining of MET was seen in the right area but negative or weak staining in the left area in both picture A. and B. 
Table 5: Correlation between MET expression status and GC clinicopathological parameters (by applying the semiquantitative methods for evaluating MET IHC staining of the study of Tiankang Guo et al.)

\begin{tabular}{|c|c|c|c|c|}
\hline IHC (\%) & $\begin{array}{c}\text { Grouping } \\
\text { overall }\end{array}$ & $\begin{array}{c}\text { MET } \\
\text { Negative }\end{array}$ & $\begin{array}{c}\text { MET } \\
\text { Positive }\end{array}$ & $P$ value \\
\hline Pathologic features & $\mathrm{n}=816(\%)$ & $\mathrm{n}=99(12.1)$ & $\mathrm{n}=717(87.9)$ & \\
\hline Age at diagnosis & & & & 0.162 \\
\hline$\geq 60$ years & $448(54.9)$ & $61(13.6)$ & $387(86.4)$ & \\
\hline$<60$ years & $368(45.1)$ & $38(10.3)$ & $330(89.7)$ & \\
\hline Sex & & & & 0.066 \\
\hline Male & $603(73.9)$ & $81(13.4)$ & $522(86.6)$ & \\
\hline Female & $213(26.1)$ & $18(8.5)$ & $195(91.5)$ & \\
\hline Tumor location & & & & 0.008 \\
\hline GEJ & $253(31.0)$ & $43(17.0)$ & $210(83.0)$ & \\
\hline GB & $414(50.7)$ & $37(8.9)$ & $377(91.1)$ & \\
\hline GA & $149(18.3)$ & $19(12.8)$ & $130(87.2)$ & \\
\hline Lauren classification & & & & 0.127 \\
\hline Intestinal & $318(39.0)$ & $33(10.4)$ & $285(89.6)$ & \\
\hline Mixed & $233(28.6)$ & $25(10.7)$ & $208(89.3)$ & \\
\hline Diffuse & $265(32.5)$ & $41(15.5)$ & $224(84.5)$ & \\
\hline Tumor differentiation & & & & 0.324 \\
\hline Well & $29(3.6)$ & $6(20.7)$ & $23(79.3)$ & \\
\hline Moderately & $166(20.3)$ & $18(10.8)$ & $148(89.2)$ & \\
\hline Poorly & $621(76.1)$ & $75(12.1)$ & $546(87.9)$ & \\
\hline Clinical stages & & & & 0.107 \\
\hline I/II & $395(48.4)$ & $40(10.1)$ & $355(89.9)$ & \\
\hline III/IV & $421(51.6)$ & $59(14.0)$ & $362(86.0)$ & \\
\hline Clinical stages & & & & 0.006 \\
\hline I & $233(28.6)$ & $14(6.0)$ & $219(94.0)$ & \\
\hline II & $162(19.9)$ & $26(16.0)$ & $136(84.0)$ & \\
\hline III & $408(50.0)$ & $58(14.2)$ & $350(85.8)$ & \\
\hline IV & 13(1.6) & $1(7.7)$ & $12(92.3)$ & \\
\hline pT status & & & & 0 \\
\hline pT1 & $193(23.7)$ & $10(5.2)$ & $183(94.8)$ & \\
\hline pT2 & $100(12.3)$ & $17(17)$ & 83(83) & \\
\hline pT3 & $238(29.2)$ & $42(17.6)$ & $196(82.4)$ & \\
\hline pT4 & $285(34.9)$ & $30(10.5)$ & $255(89.5)$ & \\
\hline pT status & & & & 0.058 \\
\hline pT1/2 & 293(35.9) & $27(9.2)$ & $266(90.8)$ & \\
\hline pT3/4 & $523(64.1)$ & $72(13.8)$ & $451(86.2)$ & \\
\hline pN status & & & & 0 \\
\hline pNo & $288(35.3)$ & $19(6.6)$ & $269(93.4)$ & \\
\hline $\mathrm{pN} 1 / 2 / 3$ & $528(64.7)$ & $80(15.2)$ & $448(84.8)$ & \\
\hline pN status & & & & 0.003 \\
\hline pNO & $288(35.3)$ & $19(6.6)$ & $269(93.4)$ & \\
\hline pN1 & $140(17.2)$ & $19(13.6)$ & $121(86.4)$ & \\
\hline pN2 & $152(18.6)$ & $26(17.1)$ & $126(82.9)$ & \\
\hline pN3 & $236(28.9)$ & $35(14.8)$ & $201(85.2)$ & \\
\hline
\end{tabular}


Table 6: Correlation between MET expression status and GC clinicopathological parameters (by applying the modified H-score system for evaluating MET IHC staining mentioned in the review of Luigi Marano et al.)

\begin{tabular}{|c|c|c|c|c|}
\hline IHC (\%) & $\begin{array}{c}\text { Grouping } \\
\text { overall }\end{array}$ & $\begin{array}{c}\text { MET } \\
\text { Negative }\end{array}$ & $\begin{array}{c}\text { MET } \\
\text { Positive }\end{array}$ & $P$ value \\
\hline Pathologic features & $\mathrm{n}=816(\%)$ & $\mathrm{n}=473(58.0)$ & $\mathrm{n}=343(42.0)$ & \\
\hline Age at diagnosis & & & & 0.033 \\
\hline$\geq 60$ years & $448(54.9)$ & $275(61.4)$ & $173(38.6)$ & \\
\hline$<60$ years & $368(45.1)$ & $198(53.8)$ & $170(46.2)$ & \\
\hline Sex & & & & 0.419 \\
\hline Male & $603(73.9)$ & $355(58.9)$ & $248(41.1)$ & \\
\hline Female & $213(26.1)$ & $118(55.4)$ & $95(44.6)$ & \\
\hline Tumor location & & & & 0.002 \\
\hline GEJ & $253(31.0)$ & $170(67.2)$ & $83(32.8)$ & \\
\hline GB & $414(50.7)$ & $223(53.9)$ & $191(46.1)$ & \\
\hline GA & $149(18.3)$ & $80(53.7)$ & $69(46.3)$ & \\
\hline Lauren classification & & & & 0.008 \\
\hline Intestinal & $318(39.0)$ & $164(51.6)$ & $154(48.4)$ & \\
\hline Mixed & $233(28.6)$ & $139(59.7)$ & $94(40.3)$ & \\
\hline Diffuse & $265(32.5)$ & $170(64.2)$ & $95(35.8)$ & \\
\hline Tumor differentiation & & & & 0.169 \\
\hline Well & $29(3.6)$ & $12(41.4)$ & $17(58.6)$ & \\
\hline Moderately & $166(20.3)$ & $95(57.2)$ & $71(42.8)$ & \\
\hline Poorly & $621(76.1)$ & $366(58.9)$ & $255(41.1)$ & \\
\hline Clinical stages & & & & 0 \\
\hline I/II & $395(48.4)$ & $200(50.6)$ & $195(49.4)$ & \\
\hline III/IV & $421(51.6)$ & $273(64.8)$ & $148(35.2)$ & \\
\hline Clinical stages & & & & 0 \\
\hline I & $233(28.6)$ & $107(45.9)$ & $126(54.1)$ & \\
\hline II & $162(19.9)$ & $93(57.4)$ & $69(42.6)$ & \\
\hline III & $408(50.0)$ & $264(64.7)$ & $144(35.3)$ & \\
\hline IV & 13(1.6) & $9(69.2)$ & $4(30.8)$ & \\
\hline pT status & & & & 0 \\
\hline pT1/2 & 293(35.9) & $137(46.8)$ & $156(53.2)$ & \\
\hline pT3/4 & $523(64.1)$ & $336(64.2)$ & $187(35.8)$ & \\
\hline pT status & & & & 0 \\
\hline pT1 & $193(23.7)$ & $84(43.5)$ & $109(56.5)$ & \\
\hline pT2 & $100(12.3)$ & $53(53.0)$ & $47(47.0)$ & \\
\hline pT3 & $238(29.2)$ & $156(65.5)$ & $82(34.5)$ & \\
\hline pT4 & $285(34.9)$ & 18.(63.2) & $105(36.8)$ & \\
\hline pN status & & & & 0 \\
\hline pNo & $288(35.3)$ & $142(49.3)$ & $146(50.7)$ & \\
\hline $\mathrm{pN} 1 / 2 / 3$ & $528(64.7)$ & $331(62.7)$ & $197(37.3)$ & \\
\hline pN status & & & & 0 \\
\hline pNO & $288(35.3)$ & $142(49.3)$ & $146(50.7)$ & \\
\hline pN1 & $140(17.2)$ & $77(55.0)$ & $63(45.0)$ & \\
\hline pN2 & $152(18.6)$ & $102(67.1)$ & $50(32.9)$ & \\
\hline pN3 & $236(28.9)$ & $152(64.4)$ & $84(35.6)$ & \\
\hline
\end{tabular}


overexpression and GC overall survival or disease-free survival.

The present study retrospectively evaluated the correlation of MET expression and HER2 expression. According to Table 2, although there was no significant correlation among the subgroups $(\boldsymbol{p}=0.164)$, we found that MET overexpression rate was higher in HER2 positive patients $(9.7 \%, 7 / 72)$. Similarly, other researchers revealed that the HER2-positive rate was significantly higher in MET-positive tumors than that in MET-negative tumors $(\boldsymbol{p}=0.036)$ [32]. Meanwhile previous study also reported that co-overexpression of MET and HER2 was demonstrated in small subsets of GC (22\%) associated with aggressive behavior. In these cases, combination therapy may be considered as a potential treatment option [11].

In this study, the concordance rate between MET expression and gene amplification was $94.6 \%$. Six cases with MET IHC 3+ didn't show gene amplification. These results suggest that, instead of MET gene amplification, other mechanisms such as mutation or alternative splicing were responsible for MET protein overexpression. Five cases with $M E T / C E P 7$ ratios $\geq 2$ showed MET expression with IHC $2+$, and they were low ratios with $M E T / C E P$ 7 ranging from 2.01 to 2.46 . Due to the limitation of the sample size, the relationship between MET overexpression and $M E T$ gene amplification and the definition of $M E T$ gene amplification should be further investigated in future studies with larger sample sizes.

In summary, there were $6.0 \%$ (49/816) cases showing MET overexpression (IHC 3+) in this Chinese cohort of Chinese GC without history of treatment. MET overexpression (IHC $3+$ ) was more common in cases with deeper infiltrating tumor and advanced clinical stages. $M E T$ gene amplification was the main reason for MET overexpression. MET overexpression could serve as a prognostic biomarker and a potential therapeutic target for gastric cancer.

\section{MATERIALS AND METHODS}

\section{Samples}

A total of 1206 patients with primary GC, who were diagnosed by postoperative pathology, between January 2014 and January 2015, at the Department of Pathology, Cancer Hospital, Chinese Academy of Medical Sciences, Beijing, China, were screened in this retrospective study. In total, 816 patients without history of neoadjuvant chemotherapy, radiotherapy and endoscopic submucous resection were included in this study. All tumor samples were fixed in $10 \%$ neutral buffered formalin for 24-48 hours and embedded in paraffin. MET and HER2 IHC staining were routinely performed in all tumor samples, and the MET, HER2 IHC slides and the relevant hematoxylin and eosin (H\&E) staining slides were assessed independently by two pathologists. Clinicopathological parameters including age at diagnosis, sex, tumor localization, histological classification, Lauren's classification, pathological TNM stage and clinical stages were also recorded.

\section{Tissue microarrays}

A total of 240 formalin-fixed paraffin-embedded samples were randomly selected to construct tissue microarrays (TMA). Two tumor cores of $1.0 \mathrm{~mm}$ diameter were taken from each sample based on H\&E staining for conducting IHC staining and dual-color silver in situ hybridization (DISH) analysis.

\section{Immunohistochemistry}

Expression of MET was evaluated by IHC analysis using rabbit monoclonal primary antibody against MET (SP44; Ventana, Tucson Arizona). Automated IHC was performed on 4- $\mu$ m-thick sections using the Ventana Benchmark ULTRA automated slide processing system according to the manufacturer's instructions. A 4-step scoring system was used as follows: no cell membrane and/or cytoplasm staining or cell membrane and/or cytoplasm staining in $<10 \%$ of tumour cells (score 0 ), faint/barely perceptible partial cell membrane and/or cytoplasm staining in $>10 \%$ of tumour cells (score $1+$ ), weak-to-moderate staining of the entire cell membrane and/or cytoplasm in $>10 \%$ of tumour cells (score $2+$ ), and strong staining of the entire cell membrane and/or cytoplasm in $>10 \%$ of tumour cells (score $3+$ ). MET overexpression negative is defined for patient with IHC staining scores of $0,1+$ and $2+$, and positive if IHC staining scores of $3+$ (Figure 1). Signal localization (cell cytoplasm or membrane) was also recorded for MET positive cases. We use Hofmann's criteria for HER2 IHC scoring [22]. TMA cores' IHC scores were evaluated based on staining intensity $(0$, no staining; $1+$, faint staining; $2+$, weak or moderate staining; $3+$, strong staining) and the stronger intensity of the two scores is the final IHC result of the sample.

\section{Dual-color silver in situ hybridization}

Dual-color silver in situ hybridization (DISH) analysis was carried out with the MET DNA probe kit and procedures (Ventana). The kit contains dual-colorlabeled DNA probes, MET gene (labeled with Spectrum Black) and CEP 7 (chromosome 7 enumeration probe, labeled with Spectrum Red). Pretreatment was carried out with the Paraffin Pretreatment Kit. The MET signals and CEP 7 signals of 20-40 nuclei of gastric tumor cells in different areas were counted using a LEICA DM3000 light microscope $\times 400$. The $M E T / C E P 7$ ratios were interpreted as follows: a $M E T / C E P 7$ ratios $\geq 2$ was defined as amplification of the $M E T$ gene, while a ratio lower 
than 2 was defined as no amplification of the MET gene (Figure 2).

Both the IHC scoring and DISH analysis were performed microscopically by two independent pathologists who were blinded to the clinical characteristics of each individual patients. The case-bycase final consensus result was discussed and determined in a common session.

\section{Statistic analysis}

Statistical analysis was carried out using SPSS 21.0 statistical software (SPSS, Inc., Chicago, IL). Statistical associations between clinicopathological characteristics and MET status were assessed using the $\chi 2$ test or Fisher's exact test (if subgroup figure is below expectation). All tests were two-sided, with significance level of 0.05 . Kappa analysis was also conducted to assess the concordance of MET overexpression and MET gene amplification.

\section{Abbreviations}

MET, mesenchymal-epithelial transition factor; GC, gastric adenocarcinoma; IHC, immunohistochemistry; DISH, dual-color silver in situ hybridization; HER2, human epidermal growth factor receptor type 2; GEJ, gastroesophageal junction; GB, gastric body; GA, gastric antrum; TNM, tumor, node and metastasis; TMA, Tissue Microarray.

\section{ACKNOWLEDGMENTS}

We thank all study participants of the Department of Pathology for their contributions to this project.

\section{CONFLICTS OF INTEREST}

The authors have declared no conflicts of interest.

\section{GRANT SUPPORT}

This study was supported by grants from the Beijing Hope Run Special Fund (LC2012A08) and the Youth Backbone Program (to Jianming Ying) of Cancer Hospital, CAMS, Beijing.

\section{Author contributions}

Jianming Ying conceived and designed the study. Jing Zhang, Lei Guo and Xiuyun Liu performed the experiments.

Jing Zhang wrote the paper.

Jianming Ying and Wenbin Li reviewed and edited the manuscript.

All authors read and approved the manuscript.

\section{REFERENCES}

1. Torre LA, Bray F, Siegel RL, Ferlay J, Lortet-Tieulent J, Jemal A. Global cancer statistics, 2012. CA Cancer J Clin. 2015; 65:87-108.

2. Ferro A, Peleteiro B, Malvezzi M, Bosetti C, Bertuccio P, Levi F, Negri E, La Vecchia C, Lunet N. Worldwide trends in gastric cancer mortality (1980-2011), with predictions to 2015, and incidence by subtype. European journal of cancer (Oxford, England: 1990). 2014; 50:1330-1344.

3. Thiel A, Ristimaki A. Targeted therapy in gastric cancer. APMIS: acta pathologica, microbiologica, et immunologica Scandinavica. 2015; 123:365-372.

4. Bang YJ, Van Cutsem E, Feyereislova A, Chung HC, Shen L, Sawaki A, Lordick F, Ohtsu A, Omuro Y, Satoh T, Aprile G, Kulikov E, Hill J, Lehle M, Ruschoff J, Kang YK, et al. Trastuzumab in combination with chemotherapy versus chemotherapy alone for treatment of HER2-positive advanced gastric or gastro-oesophageal junction cancer (ToGA): a phase 3, open-label, randomised controlled trial. Lancet (London, England). 2010; 376:687-697.

5. Sheng WQ, Huang D, Ying JM, Lu N, Wu HM, Liu YH, Liu JP, Bu H, Zhou XY, Du X. HER2 status in gastric cancers: a retrospective analysis from four Chinese representative clinical centers and assessment of its prognostic significance. Ann Oncol. 2013; 24:2360-2364.

6. Maroun CR, Rowlands T. The Met receptor tyrosine kinase: a key player in oncogenesis and drug resistance. Pharmacol Ther. 2014; 142:316-338.

7. Graziano F, Galluccio N, Lorenzini P, Ruzzo A, Canestrari E, D'Emidio S, Catalano V, Sisti V, Ligorio C, Andreoni F, Rulli E, Di Oto E, Fiorentini G, Zingaretti C, De Nictolis M, Cappuzzo F, et al. Genetic activation of the MET pathway and prognosis of patients with high-risk, radically resected gastric cancer. Journal of clinical oncology: official journal of the American Society of Clinical Oncology. 2011; 29:4789-4795.

8. Appleman LJ. MET signaling pathway: a rational target for cancer therapy. Journal of clinical oncology: official journal of the American Society of Clinical Oncology. 2011; 29:4837-4838.

9. Zhang Z, Wang J, Ji D, Wang C, Liu R, Wu Z, Liu L, Zhu D, Chang J, Geng R, Xiong L, Fang Q, Li J. Functional genetic approach identifies MET, HER3, IGF1R, INSR pathways as determinants of lapatinib unresponsiveness in HER2-positive gastric cancer. Clinical cancer research: an official journal of the American Association for Cancer Research. 2014; 20:4559-4573.

10. Chen CT, Kim H, Liska D, Gao S, Christensen JG, Weiser MR. MET activation mediates resistance to lapatinib inhibition of HER2-amplified gastric cancer cells. Molecular cancer therapeutics. 2012; 11:660-669.

11. Ha SY, Lee J, Jang J, Hong JY, Do IG, Park SH, Park JO, Choi MG, Sohn TS, Bae JM, Kim S, Kim M, Kim S, Park CK, Kang WK, Kim KM. HER2-positive gastric cancer 
with concomitant MET and/or EGFR overexpression: a distinct subset of patients for dual inhibition therapy. International journal of cancer. 2015; 136:1629-1635.

12. Lennerz JK, Kwak EL, Ackerman A, Michael M, Fox SB, Bergethon K, Lauwers GY, Christensen JG, Wilner KD, Haber DA, Salgia R, Bang YJ, Clark JW, Solomon BJ, Iafrate AJ. MET amplification identifies a small and aggressive subgroup of esophagogastric adenocarcinoma with evidence of responsiveness to crizotinib. Journal of clinical oncology: official journal of the American Society of Clinical Oncology. 2011; 29:4803-4810.

13. Okamoto W, Okamoto I, Arao T, Kuwata K, Hatashita E, Yamaguchi H, Sakai K, Yanagihara K, Nishio K, Nakagawa $\mathrm{K}$. Antitumor action of the MET tyrosine kinase inhibitor crizotinib (PF-02341066) in gastric cancer positive for MET amplification. Molecular cancer therapeutics. 2012; 11:1557-1564.

14. Catenacci DV, Henderson L, Xiao SY, Patel P, Yauch RL, Hegde P, Zha J, Pandita A, Peterson A, Salgia R. Durable complete response of metastatic gastric cancer with antiMet therapy followed by resistance at recurrence. Cancer discovery. 2011; 1:573-579.

15. Kordes S, Cats A, Meijer SL, van Laarhoven HW. Targeted therapy for advanced esophagogastric adenocarcinoma. Critical reviews in oncology/hematology. 2014; 90:68-76.

16. Gonzalez A, Broussas M, Beau-Larvor C, Haeuw JF, Boute N, Robert A, Champion T, Beck A, Bailly C, Corvaia N, Goetsch L. A novel antagonist anti-cMet antibody with antitumor activities targeting both ligand-dependent and ligand-independent c-Met receptors. International journal of cancer. 2016

17. Yazici O, Sendur MA, Ozdemir N, Aksoy S. Targeted therapies in gastric cancer and future perspectives. World journal of gastroenterology. 2016; 22:471-489.

18. Betts G, Valentine H, Pritchard S, Swindell R, Williams V, Morgan S, Griffiths EA, Welch I, West C, Womack C. FGFR2, HER2 and cMet in gastric adenocarcinoma: detection, prognostic significance and assessment of downstream pathway activation. Virchows Archiv: an international journal of pathology. 2014; 464:145-156.

19. Wu JG, Yu JW, Wu HB, Zheng LH, Ni XC, Li XQ, Du GY, Jiang BJ. Expressions and clinical significances of c-MET, p-MET and E2f-1 in human gastric carcinoma. BMC research notes. 2014; 7:6.

20. Nagatsuma AK, Aizawa M, Kuwata T, Doi T, Ohtsu A, Fujii H, Ochiai A. Expression profiles of HER2, EGFR, MET and FGFR2 in a large cohort of patients with gastric adenocarcinoma. Gastric cancer: official journal of the International Gastric Cancer Association and the Japanese Gastric Cancer Association. 2015; 18:227-238.

21. Peng Z, Zhu Y, Wang Q, Gao J, Li Y, Li Y, Ge S, Shen L. Prognostic significance of MET amplification and expression in gastric cancer: a systematic review with metaanalysis. PloS one. 2014; 9:e84502.
22. Hofmann M, Stoss O, Shi D, Buttner R, van de Vijver M, Kim W, Ochiai A, Ruschoff J, Henkel T. Assessment of a HER2 scoring system for gastric cancer: results from a validation study. Histopathology. 2008; 52:797-805.

23. Marano L, Chiari R, Fabozzi A, De Vita F, Boccardi V, Roviello G, Petrioli R, Marrelli D, Roviello F, Patriti A. c-Met targeting in advanced gastric cancer: An open challenge. Cancer letters. 2015; 365:30-36.

24. Ha SY, Lee J, Kang SY, Do IG, Ahn S, Park JO, Kang WK, Choi MG, Sohn TS, Bae JM, Kim S, Kim M, Kim S, Park $\mathrm{CK}$, Ignatius $\mathrm{Ou} \mathrm{SH}, \mathrm{Kim} \mathrm{KM}$. MET overexpression assessed by new interpretation method predicts gene amplification and poor survival in advanced gastric carcinomas. Modern pathology: an official journal of the United States and Canadian Academy of Pathology, Inc. 2013; 26:1632-1641.

25. Fuse N, Kuboki Y, Kuwata T, Nishina T, Kadowaki S, Shinozaki E, Machida N, Yuki S, Ooki A, Kajiura S, Kimura T, Yamanaka T, Shitara K, Nagatsuma AK, Yoshino T, Ochiai A, et al. Prognostic impact of HER2, EGFR, and c-MET status on overall survival of advanced gastric cancer patients. Gastric cancer: official journal of the International Gastric Cancer Association and the Japanese Gastric Cancer Association. 2016; 19:183-191.

26. Lee HE, Kim MA, Lee HS, Jung EJ, Yang HK, Lee BL, Bang YJ, Kim WH. MET in gastric carcinomas: comparison between protein expression and gene copy number and impact on clinical outcome. British journal of cancer. 2012; 107:325-333.

27. Janjigian YY, Tang LH, Coit DG, Kelsen DP, Francone TD, Weiser MR, Jhanwar SC and Shah MA. MET expression and amplification in patients with localized gastric cancer. Cancer epidemiology, biomarkers \& prevention: a publication of the American Association for Cancer Research, cosponsored by the American Society of Preventive Oncology. 2011; 20:1021-1027.

28. Guo T, Yang J, Yao J, Zhang Y, Da M, Duan Y. Expression of MACC1 and c-Met in human gastric cancer and its clinical significance. Cancer Cell Int. 2013; 13:121.

29. Yu S, Yu Y, Zhao N, Cui J, Li W, Liu T. C-Met as a prognostic marker in gastric cancer: a systematic review and meta-analysis. PloS one. 2013; 8:e79137.

30. Sun Y, Tian MM, Zhou LX, You WC, Li JY. Value of c-Met for Predicting Progression of Precancerous Gastric Lesions in Rural Chinese Population. Chin J Cancer Res. 2012; 24:18-22.

31. Noguchi E, Saito N, Kobayashi M, Kameoka S. Clinical significance of hepatocyte growth factor/c-Met expression in the assessment of gastric cancer progression. Molecular medicine reports. 2015; 11:3423-3431.

32. Kurokawa Y, Matsuura N, Kawabata R, Nishikawa K, Ebisui C, Yokoyama Y, Shaker MN, Hamakawa T, Takahashi T, Takiguchi S, Mori M, Doki Y. Prognostic impact of major receptor tyrosine kinase expression in gastric cancer. Annals of surgical oncology. 2014; 21 Suppl 4:S584-590. 